\title{
Influence of Salicylic Acid on the Growth of Lettuce (Lactuca sativa var longifolia) During Reduced Leaf Water Potential
}

\author{
${ }^{1 * B A N K O L E, ~ A E ; ~}{ }^{1} \mathrm{UMEBESE}, \mathrm{CE} ;{ }^{2} \mathrm{FEYISOLA}, \mathrm{RT}$; ${ }^{2} \mathrm{BAMISE}$, TO \\ ${ }^{1 *}$ Department of Botany, Faculty of Science, University of Lagos, P.M.B 1029 UNILAG Post Office, Akoka, Lagos State, Nigeria. \\ ${ }^{2}$ Department of Plant Science, Faculty of Science, Olabisi Onabanjo University, P. M. B. 2002 Ago Iwoye, Ogun State, Nigeria. \\ *E-mail: gbolabim@yahoo.com
}

\begin{abstract}
Salicylic acid (SA) a signal molecule which is responsible for inducing defense mechanisms in plants and also has a protective role in stress sensitivity. A study was conducted to determine the effect of water deficit stress on the growth of Lactuca sativa L. (Lettuce) using SA $(1 \mathrm{mM}$ and $3 \mathrm{mM})$ during reduced leaf water potential. Plants were subjected to 7 days drought after four weeks of growth. Stressed plants exhibited a lower leaf water potential $\left(\psi_{\mathrm{w}}\right)$ of $-0.499 \mathrm{MPa}$ as compared with the control ( $\psi \mathrm{w}$ of $-0.460 \mathrm{MPa}$ ). Plants with lower leaf $\psi_{\mathrm{w}}$ exhibited reduction in almost all the parameters studied: $1 \mathrm{mM} \mathrm{SA}$ foliar treatment caused increase of $8 \%$ in plant height and $53.16 \%$ in plant biomass. Foliar treatment of $3 \mathrm{mM} \mathrm{SA}$ of the relative water content stimulated $13 \%$ increase in the growth as compared to the control plant which was statistically significant at $\mathrm{P}<0.05$. Overall, $\mathrm{SA}$ in stressed plant exhibited higher ameliorative capacity which has the beneficial role of mediating defense response in plants under stress.
\end{abstract}

\section{DOI: https://dx.doi.org/10.4314/jasem.v22i4.18}

Copyright: Copyright (ㅇ 2018 Bankole et al. This is an open access article distributed under the Creative Commons Attribution License (CCL), which permits unrestricted use, distribution, and reproduction in any medium, provided the original work is properly cited.

Dates: Received: 06 March 2018; Revised: 10 April: 2018; Accepted: 22 April 2018

Keywords: Water stress, Salicylic acid, Growth, Lactuca sativa

Water stress in plant is an abiotic stress that is fast becoming a very critical issue facing terrestrial ecosystem in many areas of the world. Substantial losses have been recorded both in the natural ecosystem and agricultural production (Wu et al., 2011). Water stress has the ability to affect cell enlargement more than cell division, as it is also reported to alter photosynthesis, stomata closure, translocation, carbohydrates, respiration, ion uptake, nutrients metabolism and hormones (Chaves et al., 2003).

Prolonged water stress affects both physiological and metabolic processes in plant, which can lead to reduction in plant productivity and eventual death. Osmotic adjustment is an important metabolic processes in plant adaptation to drought stress as it synthesis and accumulates small compatible solutes such as proline, glycine betaine, sugars and some inorganic ions (Chaves at al., 2003; Hare et al., 1998; Bray, 1997).

Salicylic acid (SA) act as a signal molecule in the induction of defense mechanisms in plants (Raskin, 1992; Shah, 2003). It has been reported to be responsible in the regulation of certain processes in plants subjected to stress, thus improving the growth and development (Khan et al., 2015; Hayat et al., 2008; Horvath et al., 2007; Senaratna et al., 2000) .

Major role of salicylic acid include, increases in flower life, inhibits seed germination, and promotes ethylene synthesis (Singh and Usha, 2003). Studies has reported the impact of salicylic acid to give a protective effect in plants under the action of different abiotic stress such as, heat, chilling, osmotic and salt stress (Singh and Usha, 2003; Borsani et al., 2001; Janda et al., 1997).

Lettuce (Lactuca sativa L.) a member of the Asteraceae family (formally Compositae) is a selfpollinating annual plant cultivated for its edible rosette leaves and propagation is by seed (Wang et al., 2015; Judd et al., 2007). They are generally lactiferous herbs with height from 10 to $15 \mathrm{~cm}$.

The different varieties of lettuce are simply distinguished by their morphology and end users. They are well grown both in the open field and under protection and some can adapt well to warm conditions or hot weather. Lettuce is an excellent source of vitamin A, B, C, E, K, folate, iron and vegetable. The study investigates the ameliorative impact of salicylic acid on the growth of Lactuca sativa during water stress. 


\section{MATERIALS AND METHODS}

Seed collection and planting: Pure and standardized seeds of Lactuca sativa L. (Eden cultivar) were purchased from Agrotrophic seed store, Ibadan, Oyo State. The experiment was set up in the screen house with $30 \pm 5^{\circ} \mathrm{C}$ temperature, 20,000 lx light intensity and $65 \pm 5 \%$ relative humidity in the Department of Plant Science, Olabisi Onabanjo University, AgoIwoye, Ogun State, Nigeria from January 2016 March 2016. Lettuce seeds were planted in the evening at about $2-3 \mathrm{~cm}$ deep into the 80 pots of about $40 \mathrm{~cm}$ in diameter. They were filled with sieved $1 \mathrm{~kg}$ topsoil and manure was added to the soil in the preparation for planting. Seedlings were thinned into 5 plants per pot after three weeks of planting.

Growth Parameters: Plants were subjected to water stress for 7 days exactly 28 days after sowing. The plants were grouped into four consisting of twenty (20) plants per treatment. Treatment include water deficit $+1 \mathrm{mM}$ of SA, water deficit $+3 \mathrm{mM}$ of SA foliar spray; while the third were subjected to water deficit only; and the fourth group served as control (i.e. no treatment). All plants were daily watered $(300 \mathrm{ml})$ apart from the period of stress treatment and the plant pots were kept in the screen house throughout the period of the experiment. The plants were harvested on the last day of the stress treatment. Measurements such as plant height (shoot and root) and dry weight (shoot and root) were taken immediately after harvesting. Plants (shoot and root) were then dried in a hot air oven for 3 days at a temperature of $50^{\circ} \mathrm{C}$ after which the dry weight measurement was recorded.

Determination of Leaf Water Potential: Determination of the leaf water potential measures the degree of stress in plants using the tissue weightchange method outlined by Hopkins and Huner, (2004). About $0.5 \mathrm{~g}$ of leaf from each treatment was immersed in each of a graded series of $0.2 \mathrm{M}, 0.4 \mathrm{M}$, $0.6 \mathrm{M}$ and $0.8 \mathrm{M}$ sucrose solution containing $10 \mathrm{ml}$ in different test tubes. Immersed leaves were removed after one hour at equilibrium, then dried between filter paper and reweighed.

The Osmotic potential $\left(\psi_{\mathrm{s}}\right)$ of each sucrose solution was calculated using van't Hoff equation.

$\psi_{\mathrm{s}}=-\mathrm{iCRT}$

Where $\mathrm{i}=$ Ionization constant (for sucrose it is 1.0 because sucrose does not ionize in water); $\mathrm{C}=$ Molal concentration; $\mathrm{R}=$ the gas constant $(\mathrm{R}=0.08381$ litres bar/mole K); $\mathrm{T}=$ The absolute temperature (K) $273+$ ${ }^{\circ} \mathrm{C}$ of solution).
The change in weight was recorded and plotted against solute potential of sucrose solution. The leaf water potential $\left(\psi_{\mathrm{w}}\right)$ is estimated as equivalent to the solute potential of the solution in which there is no change in weight (the intercept on the abscissa).

Calculation Of Water Status Using Relative Water Content (Rwc): The water status of lettuce was calculated as the relative water content, which is expressed as a percentage of fully saturated shoot and root. In the determination of the relative water content, fresh shoots and roots were weighed and saturated by immersing in distilled water at a temperature between 0 and $40^{\circ} \mathrm{C}$. The saturated plants were then removed after four hours, surface dried and reweighed; it was oven dried at $50^{\circ} \mathrm{C}$ for a period of 3 days and the dry weight measured, according to the method of Slayter, (1967). RWC was calculated using the following formula:

$$
\text { RWC, } \%=\frac{F W-D W}{T W-D W} \times 100
$$

Where FW = fresh weight; DW = Dry weight; TW = Turgid weight

Determination Of Soil Moisture Content: The soil moisture $\left(\theta_{\mathrm{g}}\right)$ was determined after subjecting the plants to 7 days water stress, using the gravimetric method outlined by Johnson, (1962). The soil was weighted as fresh weight (FW) and then dried at $80^{\circ} \mathrm{C}$ for $48 \mathrm{~h}$ as dry weight (DW). The soil water content (WC) was calculated using the following formula:

$$
\mathrm{WC}, \%=\frac{\mathrm{FW}-\mathrm{DW}}{\mathrm{DW}} \times 100
$$

Statistical Analysis: All experiments was done in a completely randomized design. Data obtained were subjected to a one-way ANOVA. Each data point was the mean average of three replicates $(5$ pots/replicates). Comparisons with $\mathrm{P}$ values $<0.05$ were considered significantly different.

\section{RESULTS AND DISCUSSION}

Generally, water limitation significantly reduced entire growth of Lettuce that were subjected to water deficit. The result for the response of lettuce under water stress to the exogenous application of salicylic acid is as follows: 


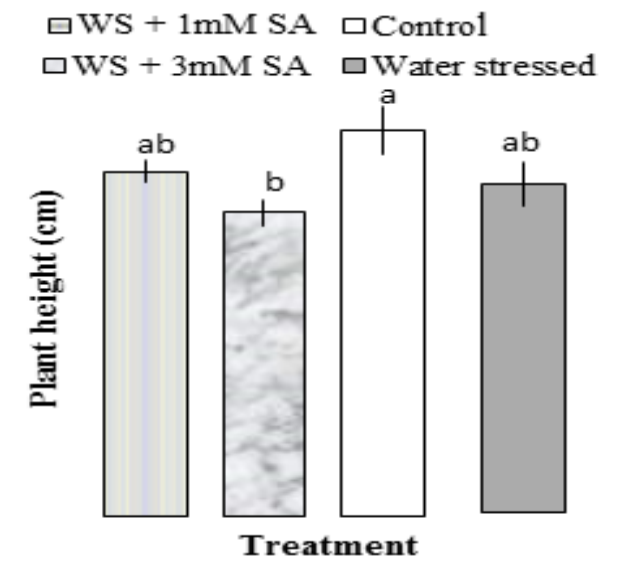

Fig 1: The plant height $(\mathrm{cm})$ of lettuce subjected to water stress and salicylic acid (SA) treatment. Mean values with similar alphabet are not significantly different at $\mathrm{P}<0.05$.

Plant biomass was significantly reduced by water stress which correspond to the low water potential induced by the 7 days water deficit (Figure 2). Growth which is an energy requiring process are limited by water stress since there is reduction of $\mathrm{CO}_{2}$ fixation and $\mathrm{NADP}^{+}$regeneration of the calvin cycle resulting to an over reduced photosynthetic electron transport chain (Kalra, 1995). However, treatment with $1 \mathrm{mM}$ SA significantly increased $(\mathrm{P}<0.05)$ plant biomass values to the control value Fig 1 and 2.

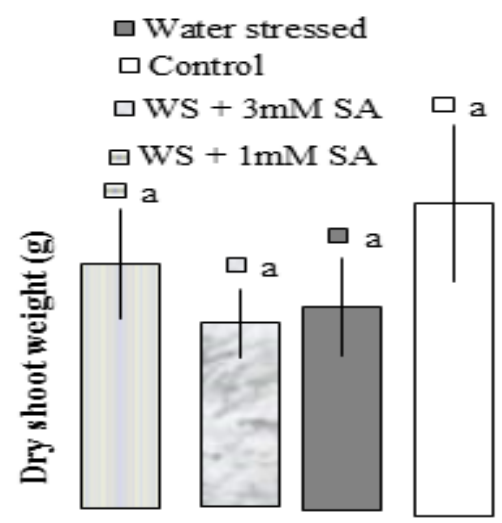

Treatment

Fig 2: Dry shoot weight of lettuce subjected to water stress (WS) and Salicylic acid (SA), values having similar alphabet are not significantly different at $\mathrm{P}<0.05$

Consideration of the relative water content in the leaves is probably the most appropriate measure of plant water status for the physiological consequences of cellular water deficit. Relative water content (RWC) of the experimental plants was significantly higher $(\mathrm{P}<0.05)$ in $3 \mathrm{mM}$ SA as shown in Table 2.

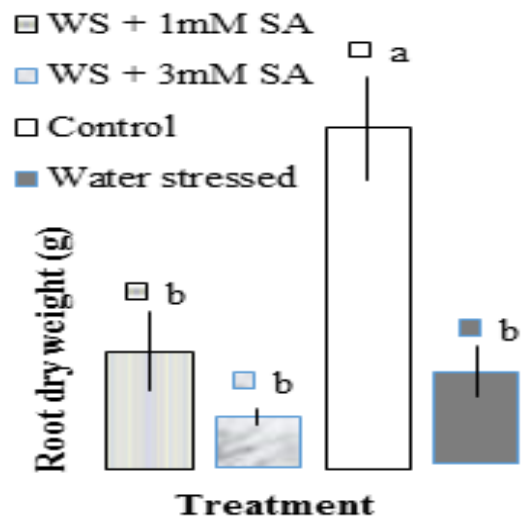

Figure 3: Dry root weight of lettuce subjected to water stress (WS) and Salicylic acid (SA), values having similar alphabet are not significantly different at $\mathrm{P}<0.05$

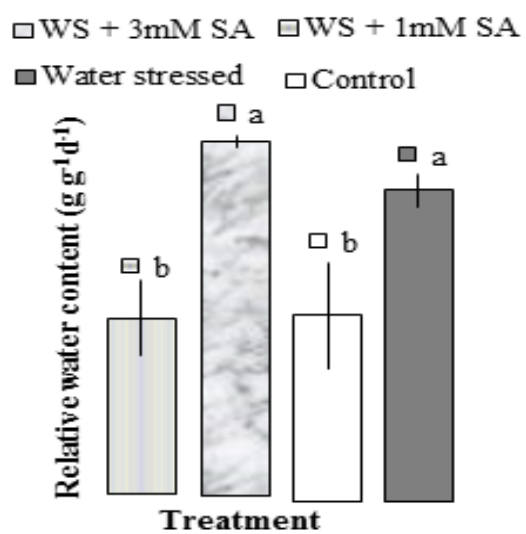

Figure 4: Relative water content (RWC) of lettuce subjected to water stress (WS) and Salicylic acid (SA), values having similar alphabet are not significantly different at $\mathrm{P}<0.05$.

There was however no significant difference between the mean fresh and dry root weight as compared to the control group which was statistically higher at $\mathrm{P}<$ 0.05 .

However, there was no significant different $(\mathrm{P}>0.05)$ in $1 \mathrm{mM} \mathrm{SA}$ and the control plants. On the other hand, there was no significant difference in the mean values of fresh and dry shoot weight and shoot turgid weight plant (Table 1). Water stress reduced the percentage relative water content of the shoot. However, $3 \mathrm{mM}$ SA slightly enhanced the shoot relative water content of lettuce than the control, while, $1 \mathrm{mM}$ SA treated plant was briefly enhanced, but with a value lesser to that of the control. 


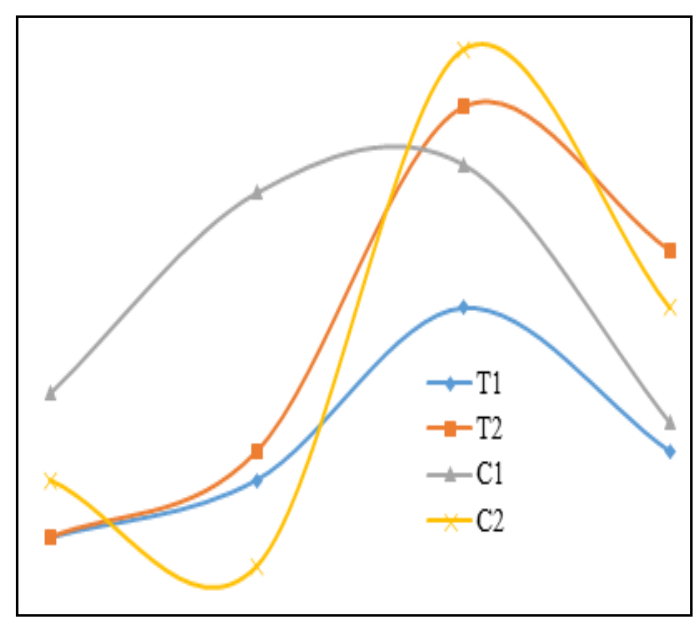

Fig 5: Leaf water potential of lettuce subjected to water deficit

Table 1: Leaf water potential of Lettuce subjected to water stress (WS) and salicylic acid (SA) treatment.

\begin{tabular}{ll}
\hline Treatment & Water Potential (MPa) \\
\hline Control & $-0.450^{\mathrm{a}}$ \\
Water stress & $0.466^{\mathrm{a}}$ \\
Water stress + 1mM SA & $-0.499^{\mathrm{b}}$ \\
Water stress + 3mM SA & $-0.461^{\mathrm{a}}$ \\
\hline
\end{tabular}

Superscripts with same letters at each treatment are not significantly different at $\mathrm{p}<0.05$. Figure 5 and Table 1 show the values of the leaf water potential of lettuce subjected to water stress and SA treatment. The values of the leaf water potential are indicated by the intercepting figures of the $\mathrm{X}$-axis abscissa on the graph. The change in the weight of the tissues of the plants subjected to water stress Overall, water stress caused a decrease in the leaf water potential of the stressed plant.

Soil moisture content in dry weight basis of lettuce subjected to water stress and SA treatment. Figure 6 indicates the level at which moisture is lost in each of the treatment during water stress. No loss of water was observed in the control, however, a significant and relatively loss of moisture content was observed in the 3mM SA treated plant.

Plant growth and development is a complex phenomenon that is often determined by different exogenous and endogenous factors. The role of salicylic acid in the regulation of the physiological processes as well as on the growth and development of plants has been reported.

This study has shown that exogenous application of SA has positive effects on Lactuca sativa (Eden cultivar) plant during water stress.

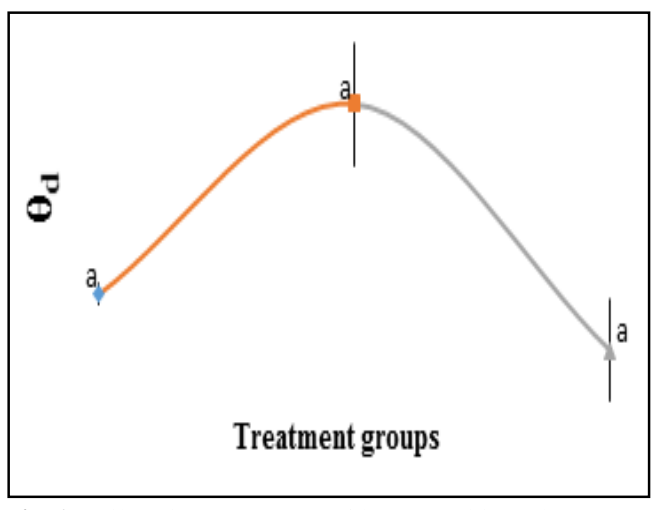

Fig 6: Soil moisture content of lettuce subjected to water deficit in sucrose solutions of varied potential was graduated on the Y-axis.

Table 2: Soil pH of plants subjected to water stress. Water stress increased the soil $\mathrm{pH}$ of the stressed plants in comparison with the control group.

\begin{tabular}{ll}
\hline Treatment & Soil pH \\
\hline Control & 8.92 \\
Water stress & 9.65 \\
Water stress + 1mM SA & 9.03 \\
Water stress + 3mM SA & 9.44 \\
\hline
\end{tabular}

However, SA application slightly alleviated the effect of water potential in lettuce which caused much growth and yield reduction during water stress.

This finding corroborates the report of Krause, 1994, that water stress significantly reduced the plant height of Allium cepa, but the stress was alleviated through exogenous application of salicylic acid. Biomass of lettuce plant suffered a significant reduction during water deficit. This is in agreement with the findings of Ahmad et al., (2014) that plant biomass was significantly reduced by water deficit which corresponds to the low water potential induced by the 7 days water deficit. However, exogenous application of $3 \mathrm{mM}$ SA alleviated the effect of water stress; as reported by Umebese and Bankole, (2013) that salicylic acid induced salinity tolerance and increased biomass of Torreya grandis. The leaf water potential of the stressed plants was significantly reduced during the water deficit. Senaratna et al., (2000) explained that water stress caused a significant reduction in the water potential of tomato plants, while SA treatment increase the water potential value of the plants at about $20.9 \%$ higher than the control. According to Li et al., (2014), who reported that leaf relative water content is an important physiological indicator that helps in the determination of the tolerance of plants to stress. Exogenous application of SA boosted the relative water content of water stressed plants. SA treatment has been reported to be able to enhance the maintenance of high relative water content of stressed plants compared to the ones without SA (Capitani et al., 2009). In a contrast report by Sanchez- Blanco et 
al., (2004), the relative water content of Zea mays during water stress was not altered.

From the study, the screen house experiment show that water stress led to a great reduction in the soil moisture content. The rate of transpiration is highly dependent on the temporal in soil moisture content. High moisture content leads to increased flow from bulk soil to root area (Wallach et al., 2010; Doussan et al., 2006; Kramer and Boyer, 1995). However, reduction in soil water content during stress results in reduction of the flow rate of water from soil bulk to root area, arising from soil resistance to water flow. Transpiration rate of the plant therefore reduced despite the increase in the evaporation demand (Wallach et al., 2010). Decrease in soil water content also reduces inflow of carbon dioxide into the leaves; and spares more electrons for the formation of active oxygen species (Farooq et al., 2009). Reduction in the soil water content also led to the decrease in the absorption (in ionic form) and utilization of nutrients, since water is needed to dissolve and transfer nutrients from the soil bulk to the root area.

Conclusion: Water stress has been recognized as a big threat to plant survival. Plants therefore induce several physiological, biochemical processes and molecular mechanism to survive these threats. This study has shown that water deficit results in the reduction of available moisture (water) in the soil and leaf water potential. Also, salicylic acid is a compound capable of reducing the effect of the stress. Overall, $3 \mathrm{mM}$ exogenous application of salicylic acid proved to be more effective in the reduction of the effect of water stress on Lactuca sativa L. in this study.

\section{REFERENCES}

Ahmad, MA; Murali, PV; Marimuthu, G (2014). Impact of salicylic acid on growth, photosynthesis and compatible solute accumulation in Allium cepa L. Subjected to drought stress. Int Jour of Agric and Food Sci 4(1): 22-30.

Borsani, O; Valpuesta, V; Botella, MA (2001). Evidence for a role of salicylic acid in the oxidative damage generated by $\mathrm{NaCl}$ and osmotic stress in Arabidopsis seedlings. Plt Physiol. 126: 1024-1030.

Bray, EA (1997). Plant responses to water deficit. Trends in Plt Sci 2: 48-54.

Capitani, D; Brilli, F; Mannina, L; Proietti, N; Loreto, F (2009). In Situ Investigation of Leaf Water Status by Portable Unilateral Nuclear Magnetic Resonance. Plt Physiol 149: 1638-1647.
Chaves, MM; Maroco, JP; Pereira, JS (2003). Understanding plant responses to drought from genes to the whole plant. Functional Plt Biol 30: 239-264.

Doussan, C; Pierret, A; Garrigues, E (2006). Water uptake by plant roots: II. Modelling of water transfer in the soil-root system with explicit account of flow within the root system: comparison with experiments. Plt and Soil 283: 99-117.

Farooq, M; Wahid, A; Kobayashi, N; Fujita, D; Basra, SMA (2009). Plant drought stress: effects, mechanisms and management. Agronomy for Sustainable Development, Springer Verlag/EDP Sciences/INRA vol. 29 (1), pp.185-212.

Hare, PD; Cress, WA; Van Staden, J (1998). Dissecting the role of osmolyte accumulation during stress. Plt Cell and Environ 21: 535-553.

Hayat, S; Hasan, SA; Fariduddin, Q; Ahmad, A (2008). Growth of tomato (Lycopersicon esculentum) in response to salicylic acid under water stress. J. Plant Interact 3(4): 297-304.

Hopkins, WG; Hüner, NPA (2004). Introduction to plant physiology. John Wiley and Sons, Inc. USA. pp. 539-540.

Horvath, E; Pal, M; Szalai. G; Paldi, E; Janda, T (2007). Exogenous 4- hydroxybenzoic acid and salicylic acid modulate the effect of short term drought and freezing stress on wheat plants. Biol. Plant 51: 480- 487.

Janda, T; Szalai, G; Tari, I; Paldi, E (1999). Hydroponic treatment with salicylic acid decreases the effect of chilling injury in maize (Zea mays L.) plants. Planta 208: 175-180.

Johnson, AI (1962). Methods of Measuring Soil Moisture in the Field, contributions to the hydrology of the United States geological survey water-supply, Third printing U.S. Government printing office: $899 \mathrm{pp}$.

Judd, WS; Campbell, C; Kellogg, EA; Stevens, PF; Donoghue, MJ (2007). Plant systematics: a phylogenetic approach. Sinauer Assoc, Sunderland 620pp. 
Kalra, YP (1995). Determination of pH of Soils by Different Methods: Collaborative Study. J. AOAC Inter. 78(2): 310-323.

Khan, MIR; Fatma, M; Per, TS; Anjum, NA; Khan, NA (2015). Salicylic acid-induced abiotic stress tolerance and underlying mechanisms in plants. Front. Plant Sci. 6:46-52.

Kramer, PJ; Boyer, JS (1995). Water relations of plants and soils. London: Academic Press.482pp.

Krause, GH (1994). The role of oxygen in photoinhibition in photosynthesis.In: Foyer, C.F and Mullaneaux, C.W (eds) causes of photooxidative stress and amelioration of defence systems in plants. Pp43-76 CRC Press Boca Ratoa.

Li, T; Hu, Y; Du, X; Tang, H; Shen, C (2014). Salicylic Acid Alleviates the Adverse Effects of Salt Stress in Torreya grandis cv. Merrillii Seedlings by Activating Photosynthesis and Enhancing Antioxidant Systems. PLoS ONE 9(10): e109492. doi:10.1371/journal.pone.0109492

Raskin, I (1992). Role of salicylic acid in plants. Ann Rev of Plt Physiol and Plt Mol Biol 43: 439- 463.

Sánchez-Blanco, MJ; Rodríguez, P; Morales, MA; Ortuño, MF; Torrecillas, A (2002). Comparative growth and water relation of Cistus albidus and Cistus monspeliensis plants during water deficit conditions and recovery. Plant Sci. 162, 107-113.

Senaratna, T; Touchell, D; Bunn, E; Dixon, K (2000). Acetyl salicylic acid (aspirin) and salicylic acid induce multiple stress tolerance in bean and tomato plants. Plant Growth Regal. 30: 157-161.
Shah, K; Kumar, RG; Verma, S; Dubey, RS (2001). Effect of cadmium on lipid peroxidation, superoxide anion generation and activities of antioxidant enzymes in growing rice seedlings. Plt Sci 161(6): 1135-1144.

Singh, B; Usha, K (2003). Salicylic acid induced physiological and biochemical changes in wheat seedlings under water stress. Plant Growth Regal. 39: 137-141.

Slatyer, RO (1967). Plant- Water Relationships. London. Academic. 366pp.

Umebese, CE; Bankole, AE (2013). Impact of salicylic acid on antioxidants, biomass and osmotic adjustments in Vigna unguiculata (L. walp) during water deficit stress. Afr J. Biotech 12(33): 5200-5207.

Wallach, R; Da-Costa, N; Raviv, M (2010). Development of synchronized, autonomous, and self-regulated oscillations in transpiration rate of a whole tomato plant under water stress. Jour of Exptal Bot 61(12): 3439-3449.

Wang, X; Zhou, B; Sun, X; Yue, Y; Ma, W; Zhao, M (2015). Soil Tillage Management Affects Maize Grain Yield by Regulating Spatial Distribution Coordination of Roots, Soil Moisture and Nitrogen Status. PLoS ONE 10(6): e0129231.

Wu, J; Liu, Y; Tang, L; Zhang, FL; Chen, F (2011). A study on structural features in early flower development of Jatropha curcas L. and the classification of its inflorescences. Afr. J. Agric. Res. 6 (2): 275-284. 